\title{
The International Classification of Functioning, Disability and Health as Applied to Parkinson's Disease: A Literature Review
}

\author{
Audrin Said Vojciechowski', Talita Gianello Gnoato Zotz², Ana Paula Cunha Loureiro³, \\ Vera Lúcia Israel ${ }^{*}$ \\ ${ }^{1}$ Physical Education Postgraduate Program, Federal University of Parana (UFPR), Curitiba, Brazil \\ ${ }^{2}$ Physiotherapy Department, Federal University of Parana (UFPR), Curitiba, Brazil \\ ${ }^{3}$ Department of Physical Therapy, School of Health and Biosciences, Pontifical Catholic University of Paraná \\ (PUCPR), Curitiba, Brazil \\ ${ }^{4}$ Physical Education Postgraduate Program and Physiotherapy Department, Federal University of Parana \\ (UFPR), Curitiba, Brazil \\ Email: asaidvoj@gmail.com, talita.gnoato@gmail.com, anna.loureiro@gmail.com, viveral.israel@gmail.com
}

Received 14 February 2016; accepted 24 May 2016; published 27 May 2016

Copyright (C) 2016 by authors and Scientific Research Publishing Inc.

This work is licensed under the Creative Commons Attribution International License (CC BY). http://creativecommons.org/licenses/by/4.0/

(c) (i) Open Access

\section{Abstract}

Objective: The objective was to describe and quantify the development of the use of the International Classification of Functioning, Disability and Health (ICF), and portray the different components that have been used in the case of Parkinson's disease (PD). Method: A literature review was carried out as from articles published in the electronic databases PubMed, Cochrane, SciELO (Scientific Electronic Library Online) and PEDro (Physiotherapy Evidence Database). The following descriptors were used: "Parkinson disease", "ICF", "Doença de Parkinson" and "CIF", combining them by the use of "and". The search covered the period from October 2014 to March 2015. Results: 50 scientific articles were found, which were evaluated by means of a thematic interpretive reading of the title and summary, finally arriving at 4 articles which related ICF to PD. In sequence the contents of the 4 articles were evaluated: organizing the author, year published, type of study, objective, methodology, ICF domains described, sample, main results and conclusions with respect to the use of ICF in PD patients, into a frame. Conclusions: The choice of ICF items provides an exact description of the functionality and incapacity domains in PD. However, it was evident that ICF had been little used to classify PD patients and help in the elaboration of intervention programs for these patients.

${ }^{*}$ Corresponding author.

How to cite this paper: Vojciechowski, A.S., Zotz, T.G.G., Loureiro, A.P.C. and Israel, V.L. (2016) The International Classification of Functioning, Disability and Health as Applied to Parkinson's Disease: A Literature Review. Advances in Parkinson's Disease, 5, 29-40. http://dx.doi.org/10.4236/apd.2016.52005 


\section{Keywords}

\section{Parkinson's Disease, Assessment, Rehabilitation, ICF}

\section{Introduction}

Only a few studies can be found in the world literature associating the application of the International Classification of Functioning, Disability and Health (ICF) with Parkinson's disease (PD), and these will be presented in this manuscript. The World Health Organization (WHO) carried out a study about health and the biopsychosocial model of human functionality and its implications with respect to diseases and deficiencies in the human life [1] [2]. Thus the interactions between human development and the environment were improved and also between human development and the tasks directly involving the health conditions of human beings [2]. It must be understood that conceptual evolution has occurred and these days the systemic or ecological or contextual human development model makes the amplified and integral understanding of human health possible, with physical, emotional, affective, psychological, cognitive and spiritual personal dimensions, as well as social dimensions, amongst others [1] [2].

From this experience a classification instrument known as the ICF was constructed which allowed for the analysis of this systemic paradigm of the development of the different life cycles and the health conditions of the people [1]. The ICF domains primarily involve the individual (structures and functions), tasks (activities and participation) and the ambient (environment) apart from personal factors. In these domains, the chapters that stand out with respect to motor activities deal with the integrities of the neuro-musculoskeletal functions related to movement, the learning capacity, the carrying out of movements and the performance in developing everyday activities related to mobility, self-care, hygiene and domestic life. This classification was used after professional evaluations by different health professionals with an interdisciplinary perspective for a greater understanding of the diagnoses of the health conditions and the functional aspects of deficiencies and their environmental and social determinants as a means of controlling health information and overall accompaniment of the human life conditions. The main objectives of ICF [1] are to: provide a scientific basis to understand health and its determinants, establish a universal language to describe health, allow for communication between the different users, allow for a comparison of the data from different countries and services, and provide a codified data systemization to widen the application spectrum of this instrument. Being a statistical, research, clinical, socio-political or pedagogical tool, it should favor an understanding of the health conditions of populations and their contexts. Adjustments to ICF are currently being studied with respect to the descriptions, use and definitions of the domains, aimed at making them more adequate as from infancy, adolescence, adulthood and old age [2]. This process of conceptual construction and reconstruction is a part of the continuous analysis of this classification instrument (ICF) which intends to be the interlocutor and integrator of health information throughout the world.

ICF was elaborated with a view to recognizing that all human beings can, at some moment in their lives, go through some situation that leaves them with a loss or decrease in health, leading to some alteration in their capabilities [3]. Such incapacities are generally felt by patients with neurological diseases, amongst which Parkinson's disease (PD) stands out, this being the second neurodegenerative disease most present in the world population [4], due to neural death of the dopaminergic cells of the midbrain substantia nigra pars compacta, causing a decrease in the production of dopamine in the nigrostriatal pathway [5] [6].

The etiology of PD has still not been defined, it being considered idiopathic. Apart from ageing, it is considered that environmental factors (infections and endogenous and exogenous immunological anomalies and other external influences) are related to the idiopathic development of the disease [7]. PD patients frequently show the cardinal signs of the disease, which are: bradykinesia, shaking at rest, rigidity, and postural instability [8], and subsequently gait freezing [9]. Thus PD patients face challenges related to their capacities, and can change from being independent people to being dependent on help to carry out movements and functions related to their everyday activities (EDAs), which can alter their affective and social relationships [9]. Hence these changes that PD patients pass through are interconnected with environmental and personal factors, with both positive and negative impacts, showing that the bio-psychosocial model (systemic) concerning the health condition in human development preconized by the use of ICF allows for a classification of the potentials of each patient according to 
his individualities [9].

According to Cardoso et al. [10], the majority of the instruments used to evaluate the performance of individuals with Parkinson's disease (PD) [11], provide information concerning the disease and its impact on the organs and/or body systems of the individual, according to an evaluation model indicated by the International Classification of Diseases (IDC-10). Thus after carrying out the traditional evaluations of each health speciality, the professional uses the ICF as an efficient means of classification that emphasizes the repercussions of PD on the patient's health condition and in the carrying out of his everyday activities. In addition, the content of ICF aids the health professionals with the register of functional information, favoring the elaboration of more adequate interventions for each patient, with emphasis on his/her real needs and hence being able to compare the gains obtained in each domain [9] [12].

Considering the possibility of using ICF to classify the impact on functionality in PD patients, the objective of this study was to describe and quantify the development of the use of the ICF, and portray the different components that have been used in Parkinson's disease (PD).

\section{Methodology}

This is a literature review [13] of studies that relate ICF to PD. The inclusion criteria for the selection of scientific articles were: original studies published between 1995 and 2015; written in English or Portuguese; articles that showed some thematic relationship between ICF and PD. Articles not published in the stipulated period, articles not presenting a relationship between ICF and PD, articles in congress proceedings and editorials and those not in the chosen language, were excluded.

The search for articles was carried out from October 2014 to March 2015, searching for scientific articles indexed in the databases: PubMed, Cochrane, SciELO (Scientific Electronic Library Online) and PEDro (Physiotherapy Evidence Database). The following descriptors were used: "Parkinson's Disease", "ICF", "Doença de Parkinson" and "CIF", combining them with the use of "and". The keywords were also defined and which databases to search in, in order to carry out the study. The initial search was for titles associated with the theme of ICF and PD, and the abstracts involving this theme were then separated. Finally the complete articles were read, organizing the author, year published, type of study, objective, methodology, ICF domains described, sample, main results and conclusions with respect to the use of ICF in PD patients, into a frame. This analysis is systematized in the results of this manuscript.

\section{Data Analysis}

The data were systematized according to the appearance of the articles and their relationship with Parkinson's disease. A data analysis was carried out stratified by the items of the ICF evaluation, with the objective of identifying the domains common to all the articles.

\section{Results}

Fifty scientific articles were found as a result of the initial search in the databases, but after an evaluation with respect to the inclusion criteria, 46 studies were excluded because they did not relate the use of ICF to PD, or did not deal with ICF or PD.

Thus 4 articles remained in the review since these studied the relation between ICF and PD, one being published in 2006, 1 in 2009, 1 in 2010 and one in 2011, 3 of them having been carried out in Milan and 1 in Holland. The objectives of the 4 articles were: 1 aiming to select the most relevant items in ICF for the classification of patients with PD and other chronic neurological diseases; and the other 3 aimed to use the ICF domains to describe the functional characteristics and profiles of patients with PD (Figure 1).

Frame 1 shows the systematization of the data of the 4 selected articles with the respective categories analyzed: type of study, objectives, methodological procedures, sample, ICF domains, principal results and conclusions of each of the four selected articles.

The objective of Wynia et al. [14] was to select ICF domains relevant and adequate for three chronic diseases. The selection was made by 37 patients and 61 professionals of the area, who filled in the questionnaires using the Delphi method, including ICF categories from "not pertinent" to "very relevant". In the case of PD, 20 items of body function (b) and structure (s), 21 items for activities (d), 17 items for participation (d) and 10 items for 


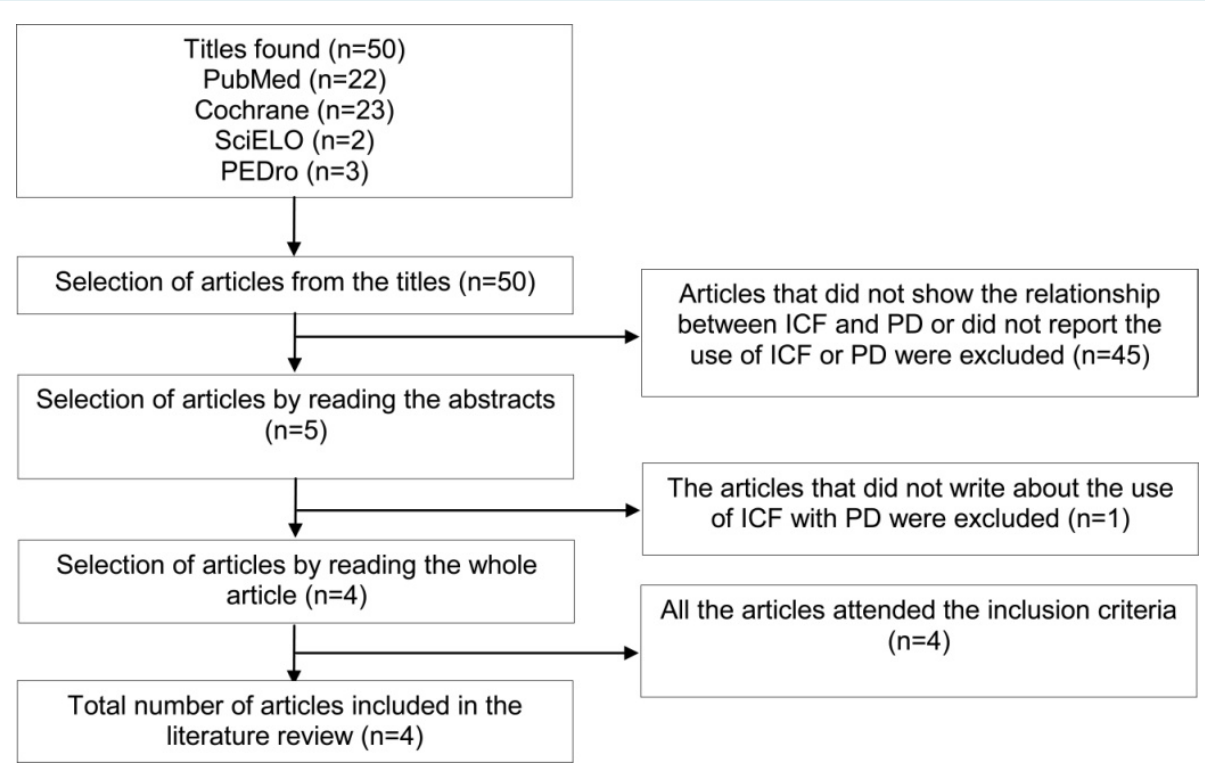

Figure 1. Flowsheet of the search and selection of articles for inclusion in the literature review.

environmental factors (e), were selected. After selecting the ICF items, the authors concluded that they covered the health conditions better than the other existing classification instruments.

In their cross-sectional type study, Leonardi et al. [15] defined their objectives as being to report and compare the functional characteristics of migraine, myasthenia gravis and PD patients by implementing ICF based methodology, although in this article they only considered PD. A total of 96 PD participants were interviewed individually. The authors observed that the majority of the body functions were classified as slight/ moderate limitations, the greatest difficulties being presented by speaking functions and neuro-musculoskeletal disorders related to movements. The activity and participation indexes (d) were related to the facilitators and barriers of the environmental factors. A moderate correlation was found between the body function deficiencies and the activity and participation indexes. The authors concluded that their choice of ICF items provided an exact description of the functionality and incapacity domains in $\mathrm{PD}$, allowing for the possibility to report the impact of environmental factors to determine the real deficiency in PD.

Raggi et al. [12] described the functioning and incapacity in PD patients according to the ICF. They carried out individual interviews about the ICF items (128 categories) in the domains of body function, body structures, activities and participation and environmental factors, in addition to the WHO Disability Assessment Schedule II (WHO-DAS II) (36 items for the evaluation of incapacity). A total of 96 patients with PD were interviewed with a mean age of 64.1 years, $33.3 \%$ were female and $48.4 \%$ were classified at stage 2 on the Hoehn \& Yahr scale $(\mathrm{H} \& \mathrm{Y})$. As the main results the most serious limitations were found in locomotion and in participation in social activities. They reached the limit of $20 \%$ of compromise in a total of 71 ICF categories, mainly in derivatives of activities and participation. A total of 26 body function (b) categories were classified, of which those presenting the most serious indexes of compromise were sleep (b134), emotional (b152), sensation of pain (b280), sexual function (b640) and muscle tone (b735); 1 body structure (s) category related to the eyes, ears and related structures; 31 categories of activities and participation (d) principally in mobility and self-help; and 13 environmental factor categories, those with the most severe indexes being health-related services, systems and policies (e580), social security services, systems and policies (e570), friends (e320), health professionals (e355) and communication products and technologies (e125). In their conclusions, the authors affirmed that PD patients have benefits in various activities in environmental factors, especially in the areas of movement, self-care and domestic life, although there are areas in the ICF in which the environmental factors were less efficient, such as, for example, in activities related to communication and personal relationships.

The research group of Raggi et al. [16] described the functional profile of PD patients and the relationships between the compromise of body functions, limitations in activities and environmental factors and the use of ICF. The method used was individual interviews with the participants, and information concerning problems with "body function" and "body structure" was obtained from the medical files of each patient. A total of 96 pa- 


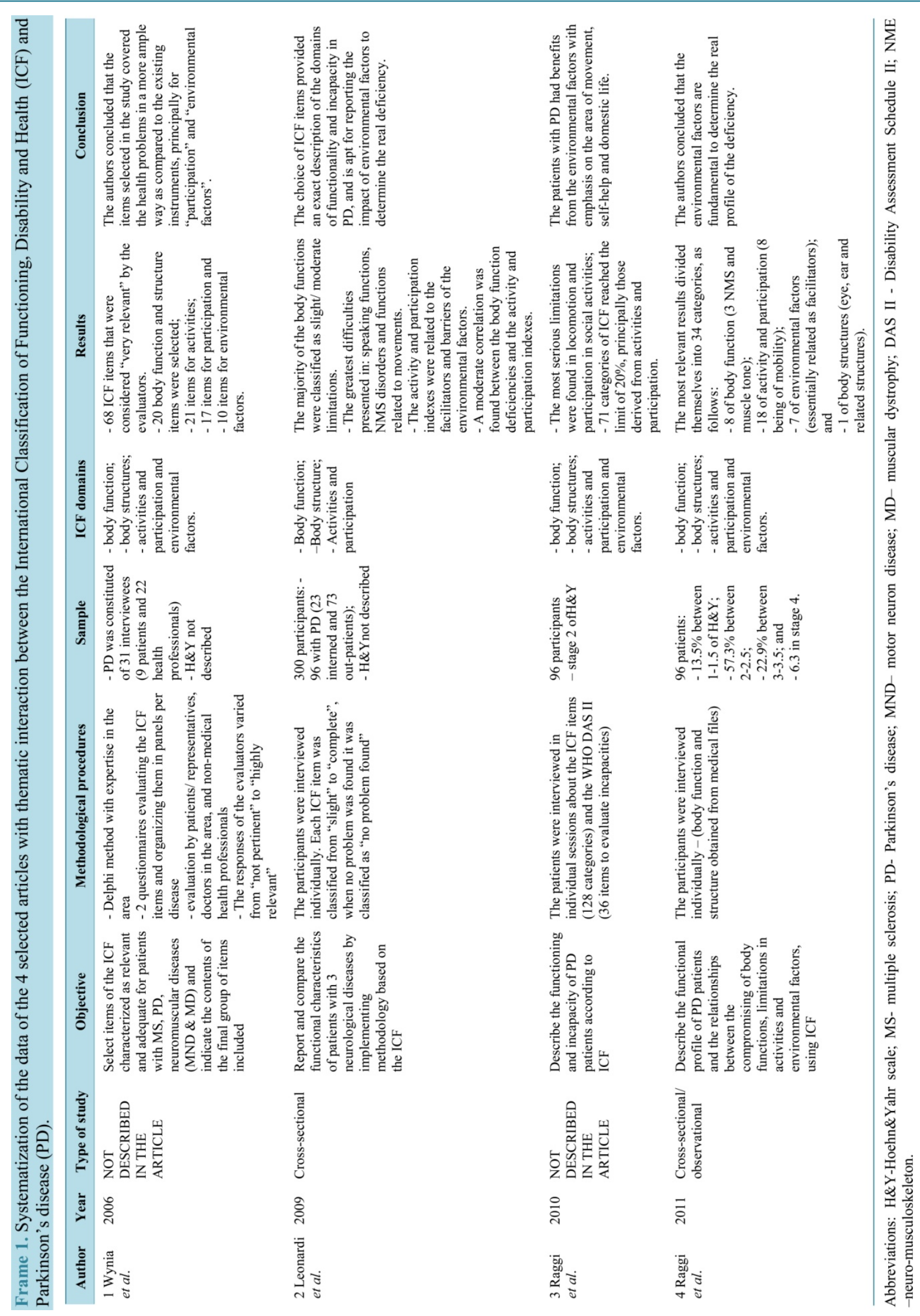


tients were included of which $66.7 \%$ were male, the mean age was 64.1 years and on the H\&Y scale $13.5 \%$ were between $1-1.5 ; 57.3 \%$ between $2-2.5 ; 22.9 \%$ between $3-3.5$; and 6.3 in stage 4 . The ICF domains observed were body function, body structure, activities and participation and environmental factors. The most relevant and most reported results were divided amongst 34 categories as follows: 8 of body function (b), especially 3 neuro-musculoskeletal categories related to movement, such as, for example, muscle tone; 18 categories of activity and participation (d) with 8 in the item of mobility; 7 environmental factor categories essentially related as facilitators; and 1 body structure category (s) such as eyes, ears and related structures. All these items were reported by more than $50 \%$ of the participants. It was concluded that environmental factors were fundamental to determine the real profile of the deficiency. Serious limitations and restrictions are a result of the joint action of body function dysfunctions and the presence of barriers.

It must be pointed out that two of the studies included in this review did not determine the degree of compromise of the individuals with PD according to the Hoehn \& Yahr scale.

With respect to the body function and structure domains (Frame 2), Wynia et al. [14] selected 20 items, the following being reported as more relevant by the authors: involuntary movements, swallowing, tolerance to exercise and sleep functions, whereas Leonardi et al. [15] found the following items to be more prevalent: emotional functions (b152), seeing (b210), pain (b280) and the eye and ear structure (s2). Raggi et al. [12] presented the following items as being more severe: sleep (b134), emotional (b152), pain (b280), sexual function (b640) and muscle tone (b735), and in another study Raggi et al. [16] found the following items: involuntary movements (b765), muscle tone (b735), seeing function (b210) and the eyes, ears and related structures (s2). The instruments used to determine the deficiencies in these domains were: the Montreal cognitive assessment (MoCA), the Mini- Balance Evaluation Systems Test (Mini-BESTest) and the muscle strength of the upper and lower limbs and hand gripping strength.

With respect to the domains of activities and participation (Frame 2), Wynia et al. [14] reported 21 and 17 items, respectively, as being relevant, the principal ones being: walk, drink, mobility at home and in buildings and mobility away from home and buildings. Leonardi et al. [15] observed greater problems with the following items: lifting and carrying objects (d430), doing housework (d640), watching (d110) and remunerative employment (d850). On the other hand Raggi et al. [12] found reduced capacity in the following: changing the basic body position (d410), maintaining a body position (d415) and moving around in different locations (d460) whereas in their other study, Raggi et al. [16] found decreased capacity in: walking (d450), lifting and carrying objects (d430), getting dressed and fine hand use (d440). The main instruments used to evaluate the conditions of the patients in these domains were: the five-times-sit-to-stand test (FTSST), UPDRS (FES1 and FOG), the gait speed test, the 6-minute walk test (6MWT), the Timed Up \& Go test and the Human Activity Profile and Parkinson's Disease questionnaires (PDQ-39).

Finally, with respect to environmental factors (Frame 2), Wynia et al. [14] found the following items as barriers: services, systems and policies related to health, individual attitudes of close family members and services, systems and policies related to social security. Leonardi et al. [15] reported the largest barriers as being due to the climate (e225), light (e240) and sound (e250). Raggi et al. [16] found the following items as barriers: products or substances for personal consumption (e110), immediate family (e310) and services, systems and policies related to health. The only study that exposed the barriers and facilitators was that of Raggi et al. [12], the items related to barriers being: friends (e320), individual attitudes if immediate family members (e410) and services, systems and policies related to transportation (e540), whilst the facilitators were: services, systems and policies related to social security (e570), services, systems and policies related to health (e580) and products or substances for personal consumption (e110).

Figure 2 shows the questionnaires and physical-functional tests most used to evaluate the PD patients and their relationships with the ICF domains.

\section{Discussion}

The present literature review provided evidence that studies are required that deal with the relationship between the ICF and Parkinson's disease. The limitation in scientific production on this subject could be due to the restricted understanding and divulging for an adequate handling of ICF and also due to the particularities associated with PD.

For PD, the H\&Y evaluation scale indicates the functionality of the patient, with implications in the relationships between the practice of physical activity and the functional capacity in PD. The present review showed 


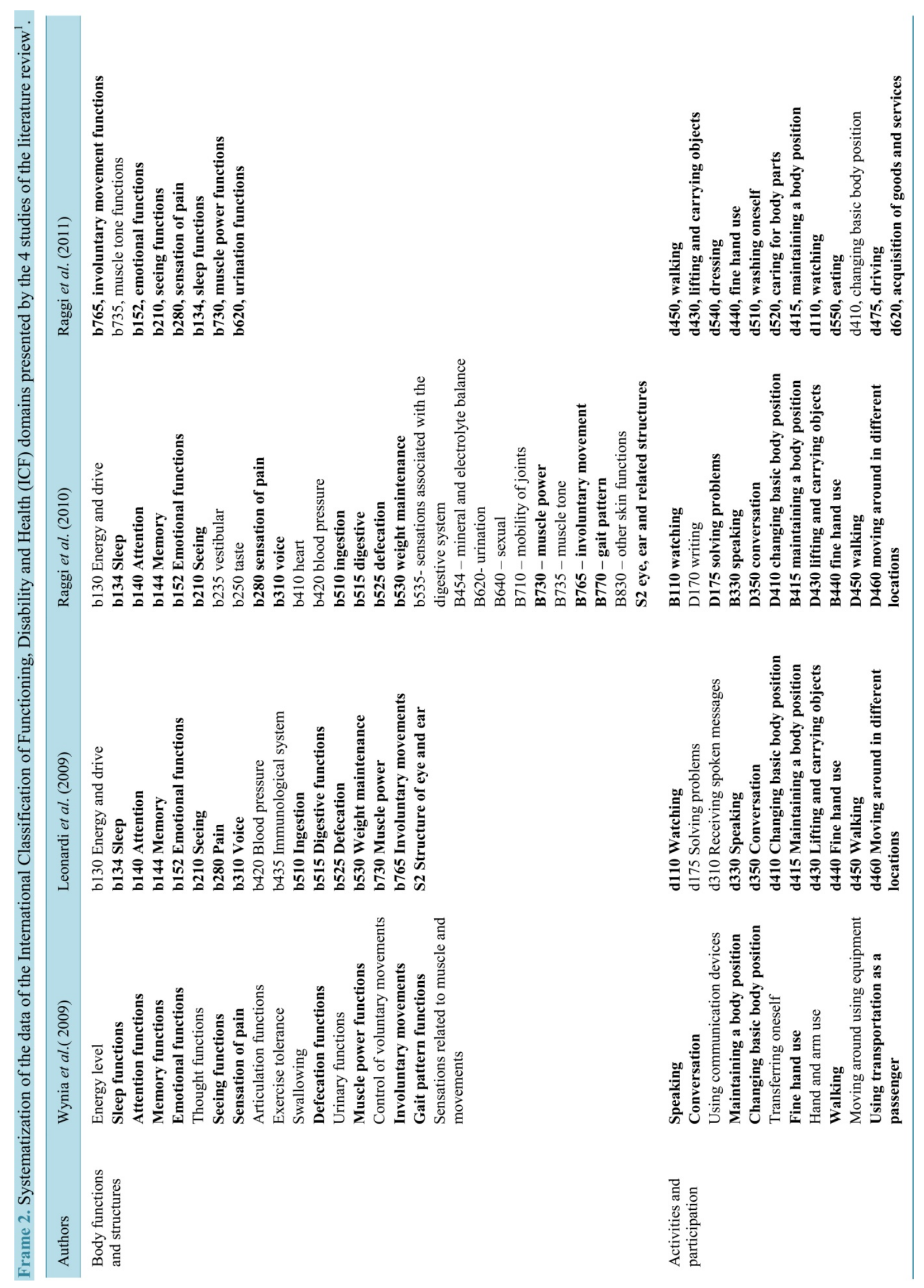



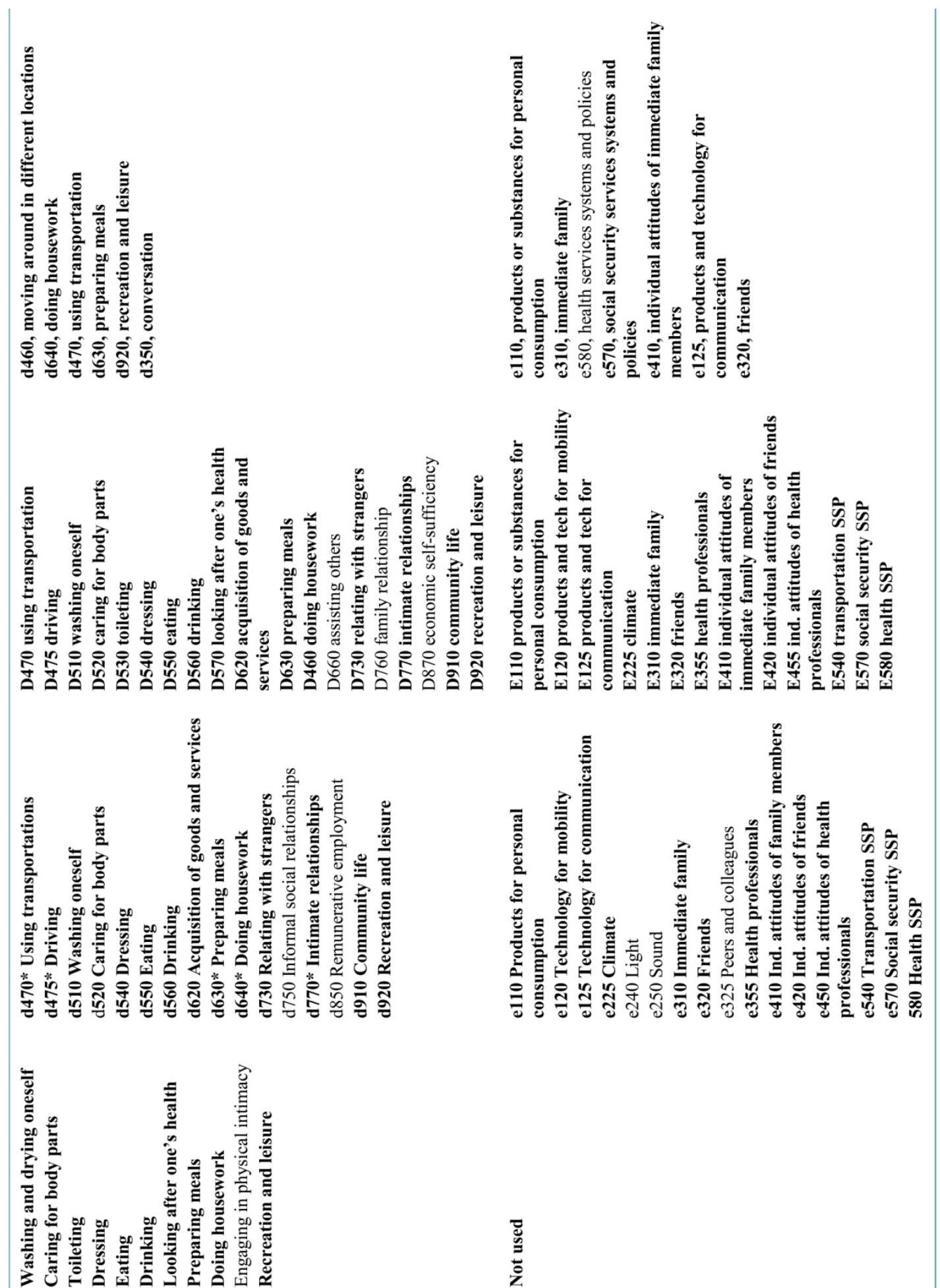

चัّ 


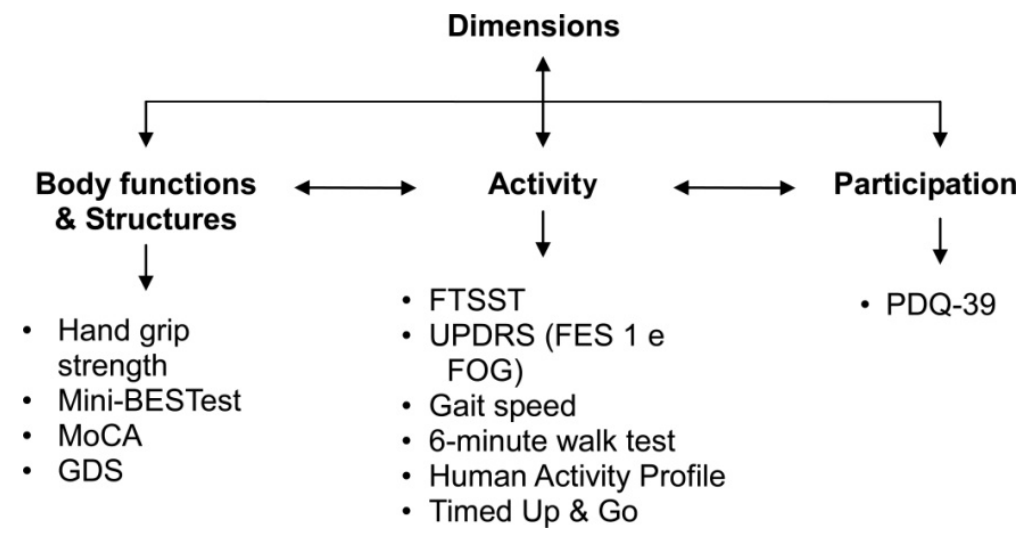

Figure 2. Questionnaires and physical-functional tests related to the ICF domains and PD [17].

that only two studies [12] [16] explained the degree of compromise of the participants according to the H\&Y scale.

Still considering studies using the correlation between ICF and PD, Ellis et al. [11] explored factors associated with physical activity in 260 individuals with PD, varying between 1 and 4 on the H\&Y scale, using ICF. These individuals were designated as "exercisers" and "non-exercisers", $63 \%$ being designated as "exercisers". Thus the authors concluded that self-efficacy, evaluated using the self-efficacy scale, of which the objective is to verify the confidence of the individual in his/her capacity to continue carrying out a task despite an obstacle, seems to be strongly associated with the ambulatory activity, suggesting that the physiotherapists should include strategies to improve the self-efficacy of an exercise during the prescription of treatment programs for this public.

The domains of body structure/ functional level of ICF have been shown to be sensitive in detecting changes after PD patients have carried out some physical activity, and also in determining small improvements, as compared to other exercise protocols for PD individuals [18].

In a systematic review based on the ICF model with respect to quality of life of individuals with PD, a strong correlation was found between the quality of life and "psychosocial function" of the participation domain and "mobility limitations" from the activities domain. With respect to the domain: body function and structure and its correlation with quality of life, it was shown that the non-motor symptoms were more closely related to a reduction in quality of life of individuals with PD than the motor symptoms. The authors concluded that this systematic review demonstrated the utility of ICF in the association of quality of life in PD [19].

In a study carried out by Holt, Wagennar \& Saltzman [20], in which the dynamic systems theory was considered, the relevance of evaluating the whole patient with respect to his/her health condition and according to the factors and dimensions with implications in the variables analyzed, was verified, where the organism and his/her personal characteristics, the environment and the task influence the functional abilities of each individual [21].

Considering the importance of evaluating the whole patient, an analysis of the social aspect in the physical activity carried out by an individual with PD, is relevant, since social isolation occurs in PD, which, for its part, leads to a decline in the carrying out of exercises [22]. Thus the emotional, informational and instrumental aspects evaluated by ICF positively influence the individual with PD to take part in physical activities [22].

In general the four articles presented here aimed to select and map the use of ICF in PD and/or other chronic neurological diseases. Cameron \& Nilsagard [23] used ICF to structure the evaluation of the lack of body equilibrium and the risk of falls in patients with, for example, multiple sclerosis, justifying this by the fact the ICF model is capable of identifying possible causes and factors that could contribute to a lack of body equilibrium, so as to indicate which would be the best evaluation test to use and the most adequate intervention program to be carried out.

As a consequence the choice of an adequate intervention to treat the limitations and/or restrictions presented by a patient would lead to an improvement in his/her quality of life. Thus the use of ICF as an instrument to measure the quality of life in neurological patients, as suggested by Faria et al. [24], is valid as an aid in the elaboration of specific instruments to determine the disease or health condition, since, as shown in the present study, a specific instrument structured by ICF to evaluate the quality of life in neurological patients provides a 
more complete evaluation than non-specific instruments not indicated by ICF.

Holt, Wagennar \& Saltzman [20] considered the dynamic systems theory and ICF, with emphasis on functionality, principally in locomotion disorders in patients with cerebral palsy and PD. The results obtained indicated the use of ICF as an instrument to analyze mobility in PD patients, considering the restricting factors, which would facilitate gait, leading one to consider aspects of the personal and everyday lives of these patients, since any cognitive alteration can change the gait pattern, thus compromising a functional activity involved in an independent life.

ICF can also be used as a means of indicating the treatment for a PD patient. For example, considering the gait disorders, the physiotherapist should indicate the best instrument to evaluate the functional abilities and capacities of the patient and his/her gait pattern, based on ICF, in order to list the most efficient and effective exercises and functional stimulation for these patients [20]. Since this is a multidimensional model of a biopsychosocial health classification, its use could be multi-professional and manage to classify the state, or better, the health condition of a PD patient in a wider manner, aiding in the elaboration of more adequate intervention programs for each patient [25].

This review showed a scarcity of studies associating ICF with PD. The authors believe this is due to the long application period demanded by ICF, and also because ICF is not in the domain of knowledge of all health professionals. The professionals prefer to use quick evaluation instruments that are frequently not sensitive enough to verify some limitation or motor ability the patient has. ICF allows one to classify the individual in all the domains that surround him/her, providing a more sensitive method to compare the results of an intervention and adequate it according to the patient's needs.

Future studies should develop an ICF core set to classify the specific health condition of patients with Parkinson's disease, as already exist for strokes, lumbago, depression, osteoarthritis and others [26]. This is necessary because the moderate quality methodology of the randomized clinical trials carried out with respect to the impacts of physiotherapy in PD, demonstrate the lack of measuring instruments capable of identifying clinically significant alterations according to ICF [27].

\section{Conclusions}

If one considers the objective of listing the possible items and domains of the ICF most adequate for the classification of individuals with PD, the articles considered in the present review are effective, and the items selected in these articles are similar with respect to the following domains: function and structure (involuntary movements, sleep, sensation of pain); participation and activities (speaking, gait and maintaining a body position) and environmental factors (transport, friendships, family relationships). It is important to consider the individual characteristics of the participants in the articles used in the present review, since the degree of compromise according to the H\&Y scale can influence interpretation of the ICF domains, and hence the degree of compromise of the individuals involved must be demonstrated.

It must be mentioned that no articles were found that compared the classification (ICF) after some interventions, in order to suggest a possible intervention time capable of altering the classification between one time and another, pre- and post-intervention.

Thus one can conclude that the choice of ICF items provides an exact description of the functionality and incapacity domains of PD. However, studies that correlate ICF with Parkinson's disease are scarce, both for the classification of these patients and as a form of aiding in the elaboration of intervention programs for each subject.

\section{References}

[1] Organização Mundial de Saúde: OMS (2003) Classificação Internacional de Funcionalidade, Incapacidade e Saúde. OMS/OPAS, EDUSP, São Paulo.

[2] Organização Mundial de Saúde: OMS (2015) Classificação Internacional de Funcionalidade, Incapacidade e Saúde. OMS/OPAS, EDUSP, São Paulo.

[3] Nubila HBV (2010) Uma introdução à CIF-Classificação Internacional de Funcionalidade, Incapacidade e Saúde. Revista Brasileira de Saúde Ocupacional, 35, 122-123.

[4] Malek, N. and Grosset, D.G. (2015) Medication Adherence in Patients with Parkinson's Disease. CNS Drugs, 29, $47-$ 53. http://dx.doi.org/10.1007/s40263-014-0220-0 
[5] Christofoletti, G., Freitas, R.T., Candido, E.R. and Cardoso, C.S. (2010) Eficácia de tratamento fisioterapêutico no equilíbrio estático e dinâmico de pacientes com doença de Parkinson. Fisioterapia e Pesquisa, 17, 259-263. http://dx.doi.org/10.1590/S1809-29502010000300013

[6] Monteiro, D., Coriolano, M.G.W.S., Belo, L.R. and Lins, O.G. (2014) Relação entre disfagia e tipos clínicos na doença de Parkinson. Revista CEFAC, 16, 620-627. http://dx.doi.org/10.1590/1982-0216201419212

[7] Dovero, S., Gross, C. and Bezard, E. (2016) Unexpected Toxicity of Very Low Dose MPTP in Mice: A Clue to the Etiology of Parkinson's Disease? Synapse, 20, 49-51. http://dx.doi.org/10.1002/syn.21875

[8] Chou, Y.H., Hickey, P.T., Sundman, M., Song, A.W. and Chen, N.K. (2015) Effects of Repetitive Transcranial Magnetic Stimulation on Motor Symptoms in Parkinson Disease: A Systematic Review and Meta-Analysis. JAMA Neurology, 72, 432-440. http://dx.doi.org/10.1001/jamaneurol.2014.4380

[9] Park, J.H., Kang, Y.J. and Horak, FB. (2015) What Is Wrong with Balance in Parkinson's Disease? Journal of Movement Disorders, 8, 109-114. http://dx.doi.org/10.14802/jmd.15018

[10] Cardoso, A.A., Magalhães, L.C., Lacerda, T.T.B. and Andrade, P.M.O. (2012) Relação entre a Avaliação da Coordenação e Destreza Motora (Acoordem) e a Classificação Internacional de Funcionalidade, Incapacidade e Saúde (CIF). Fisioterapia em Movimento, 25, 31-45. http://dx.doi.org/10.1590/S0103-51502012000100004

[11] Ellis, T., Cavanaugh, J.T., Earhart, G.M., Ford, M.P., Foreman, K.B.O., Fredman, L., Boudreaud, J.K. and Dibble, L.E. (2011) Factors Associated with Exercise Behavior in People with Parkinson Disease. Physical Therapy, 91, 1838-1848. http://dx.doi.org/10.2522/ptj.20100390

[12] Raggi, A., Leonardi, M., Ajovalasit, D., Carella, F., Soliveri, P., Albanese, A. and Romito, L. (2010) Functioning and Disability in Parkinson's Disease. Disability and Rehabilitation, 32, 33-41. http://dx.doi.org/10.3109/09638288.2010.511688

[13] Hochman, B., Nahas, F.X., Oliveira Filho, R.S. and Ferreira, L.M. (2005) Desenhos de Pesquisa. Acta Cirurgica Brasileira, 20, 2-9. http://dx.doi.org/10.1590/S0102-86502005000800002

[14] Wynia, K., Middel, B., Van Dijk, J.P., Ruiter, H.D., Lok, W., Keyser, J.H.D. and Reijneveld, S.A. (2006) Broadening the Scope on Health Problems among the Chronically Neurologically Ill with the International Classification of Functioning (ICF). Disability and Rehabilitation, 15, 28, 1445-1454.

[15] Leonardi, M., Meucci, P., Ajovalasit, D., Albanesi, F., Cerniauskaite, M., Invernizzi, V., et al. (2009) ICF in Eurology: Functioning and Disability in Patients with Migraine, Myasthenia Gravis and Parkinson's Disease. Disability and Rehabilitation, 31, S88-S99. http://dx.doi.org/10.3109/09638280903317732

[16] Raggi, A., Leonardi, M., Ajovalasit, D., Carella, F., Soliveri, P., Albanese, A. and Romito, L. (2011) Disability and Profiles of Functioning of Patients with Parkinson's Disease Described with ICF Classification. International Journal of Rehabilitation Research, 34, 141-150. http://dx.doi.org/10.1097/MRR.0b013e328344ae09

[17] REPARK-BRASIL (2013-2015) Rede Parkinson Brasil: Projeto de pesquisa "caracterização do perfil físico-funcional de indivíduos com doença de Parkinson no Brasil baseada na classificação internacional de funcionalidade, incapacidade e saúde: Um estudo multicêntrico", UFMG/Belo Horizonte e UFPR/Curitiba/Brasil.

[18] King, L.A., Salarian, A., Mancini, M., Priest, K.C., Nutt, J., Serdar, A., Wilhelm, J., Schlimgen, J., Smith, M. and Horak, F.B. (2013). Exploring Outcome Measures for Exercise Intervention in People with Parkinson's Disease. Parkinson's Disease, 2013, 1-9. http://dx.doi.org/10.1155/2013/572134

[19] van Uem, J., Marinus, J., Canning, C., van Lummel, R., Dodel, R., Liepelt-Scarfone, I., Berg, D., Morris, M.E. and Maetzler, W. (2015) Health-Related Quality of Life in Patients with Parkinson's Disease: A Systematic Review Based on the ICF Model. Neuroscience \& Biobehavioral Reviews, 61, 26-34.

[20] Holt, K.G., Wagenaar, R.O. and Saltzman, E. (2010) A Dynamic Systems: Constraints Approach to Rehabilitation. Revista Brasileira de Fisioterapia, 14, 446-463.

[21] Viotto Filho, I.A.T., Ponde, R.F. and Almeida, S.H.V. (2009) As compreensões do humano para Skinner, Piaget, Vygotski e Wallon: Pequena introdução às teorias e suas implicações na escola. Psicologia da Educação, 19, 27-55.

[22] Ravenek, M.J. and Schneider, M.A. (2009) Social Support for Physical Activity and Perceptions of Control in Early Parkinson's Disease. Disability and Rehabilitation, 31, 1925-1936.

[23] Cameron, M.H. and Nilsagard, Y.E. (2013) Measurement and Treatment of Imbalance and Fall Risk in Multiple Sclerosis Using the International Classification of Functioning, Disability and Health Model. Physical Medicine \& Rehabilitation Clinics of North America, 24, 337-354. http://dx.doi.org/10.1016/j.pmr.2012.11.009

[24] Faria, C.D.C.M., Silva, S.M., Correa, J.C.F., Laurentino, G.F.C. and Teixeira-Salmela, L.F. (2012) Identificação das categorias de participação da CIF em instrumentos de qualidade de vida utilizados em indivíduos acometidos pelo acidente vascular encefálico. Revista Panamericana de Salud Pública, 31, 338-344.

[25] Quintana, J.M., Ferreira, E.Z., Santos, S.S.C., Pelzer, M.T., Lopes, M.J. and Barros, E.J.L. (2014) A utilização da 
Classificação Internacional de Funcionalidade, Incapacidade e Saúde no cuidado aos idosos. Revista Brasileira de Enfermagem, 1, 145-152.

[26] Riberto, M. (2011) Core sets da classificação internacional de funcionalidade, incapacidade e saúde. Revista Brasileira de Enfermagem, 64, 938-946. http://dx.doi.org/10.1590/S0034-71672011000500021

[27] Kwakkel, G., de Goede, C.J. and van Wegen, E.E. (2007) Impact of Physical Therapy for Parkinson's Disease: A Critical Review of the Literature. Parkinsonism \& Related Disorders, 13, S478-S487.

http://dx.doi.org/10.1016/S1353-8020(08)70053-1 